\title{
Validity and reliability of the Farsi version of the ECOS-16 questionnaire for females with osteoporosis
}

Rahmatollah Moradzadeh, ${ }^{1}$ Nasrin Moghimi, ${ }^{2}$ Haidar Nadrian, ${ }^{3}$ Farzaneh Behrouzi, ${ }^{4}$ Tara Keshavarz ${ }^{4}$ and Parvaneh Golmohammadi

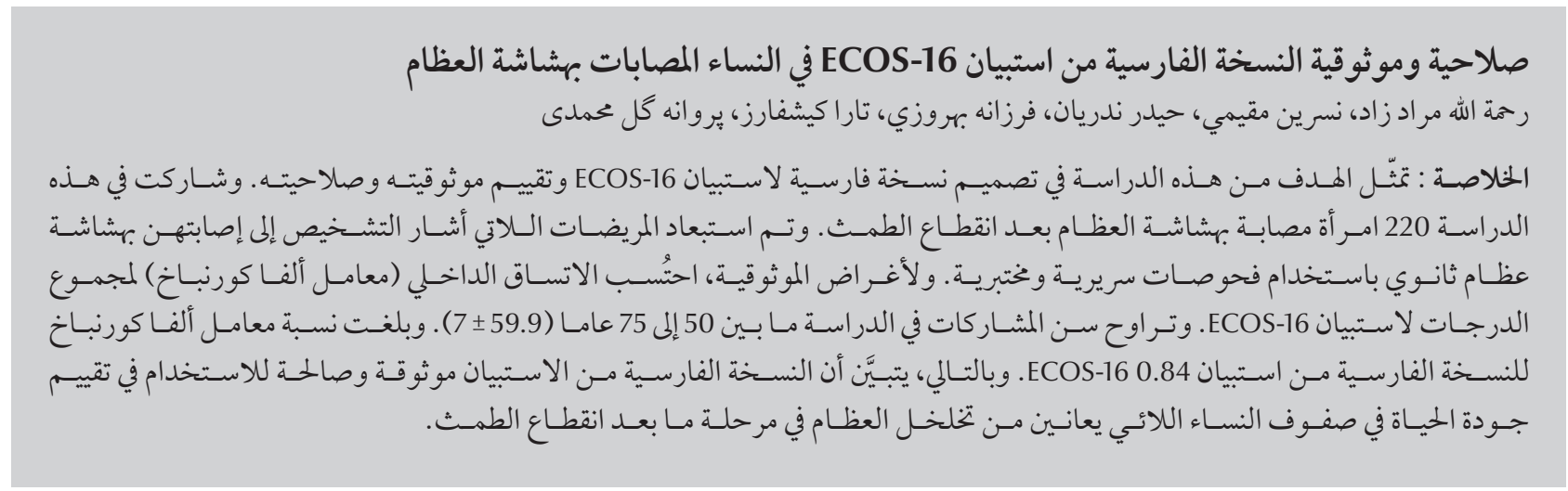

ABSTRACT The purpose of this study was to develop a Persian version of ECOS-16 Questionnaire and assess its reliability and validity. Two hundred and twenty women with postmenopausal osteoporosis were included in the study. Patients who were diagnosed as secondary osteoporosis by clinical and laboratory examinations were excluded. For reliability, an internal consistency (Cronbach's alpha coefficient) of ECOS-16 total score was calculated. The age of the study participants ranged from 50 to 75 years old $(59.9 \pm 7)$. Cronbach's alpha of the Persian version of the ECOS-16 was 0.84. Therefore, the Persian version of the ECOS-16 is a reliable and valid questionnaire to be used in the evaluation of quality of life in women with postmenopausal osteoporosis.

\section{Validité et fiabilité de la version perse du questionnaire ECOS-16 chez les femmes souffrant d'ostéoporose}

RÉSUMÉ La présente étude avait pour objectif de mettre au point une version perse du questionnaire ECOS-16 et d'évaluer sa fiabilité et sa validité. Deux cent vingt femmes souffrant d'ostéoporose post-ménopausique ont été incluses dans l'étude. Les patientes diagnostiquées avec une ostéoporose secondaire aux examens cliniques et biologiques en ont été exclues. Afin d'évaluer la fiabilité, la cohérence interne (coefficient alpha de Cronbach) du score total du questionnaire ECOS-16 a été calculée. L'âge des participantes à l'enquête était compris entre 50 et 75 ans $(59,9 \pm 7)$. L'alpha de Cronbach de la version perse du questionnaire ECOS-16 était de 0,84. La version perse du questionnaire ECOS-16 constitue donc un questionnaire fiable et valable pouvant être utilisé pour l'évaluation de la qualité de la vie des femmes souffrant d'ostéoporose post-ménopausique.

'Department of Epidemiology; School of Public Health, Arak University of Medical Sciences, Arak, Islamic Republic of Iran (Correspondence to: Rahmatollah Moradzadeh:r.moradzadeh@arakmu.ac.ir).2Department of Rheumatology, school of Medicine, Kurdistan University of Medical Sciences, Sanandaj, Iran. ${ }^{3}$ Department of Health Education \& Promotion, Faculty of Health Sciences, Tabriz University of Medical Sciences, Tabriz, Islamic Republic of Iran. ${ }^{4}$ Islamic Azad University, Sanandaj Branch, Sanandaj, Islamic Republic of Iran.

Received: 17/01/16; accepted: 17/01/17 


\section{Introduction}

Osteoporosis is a chronic and progressive disease characterized by decreased bone mass and deterioration of the microscopic structure of bone causing it to be prone to fracture (1), and consequently the condition affects quality of life $(2,3)$. It is a common disease: 1 in every 4 women and 1 in every 8 men will be affected in their lifetime (4). With the onset of menopause, bone loss in women increases considerably: in the first $5-10$ years the loss is $25-30 \%$ of trabecular bone and $10-15 \%$ of cortical bone. Therefore, postmenopausal women are at high risk of osteoporosis and its complications. According to the World Health Organization, approximately $21 \%$ of women aged $50-84$ years have osteoporosis (5), and with the growth in the elderly population up to 2025, the incidence of osteoporosisrelated fractures will double, thus the direct and indirect costs associated with these fractures will increase dramatically $(1,6)$ : it is expected that more than $75 \%$ of fractures caused by osteoporosis in the next 50 years will occur in developing countries (7).

In a comprehensive Iranian study, $50 \%$ of men and $70 \%$ of women aged 50 years and over had osteoporosis or osteopenia (8). The estimated prevalence of osteoporosis in postmenopausal women in Kurdistan province is $34.4 \%$ (9). In a 2005 Iranian study, the average cost per patient with pelvic fractures was estimated at US\$ 588 and the mean duration of hospitalization per patient was 16 days (10). In a study on the burden of osteoporosis in the Islamic Republic of Iran, the disability-adjusted life years (DALYs) was estimated at 36 761, 17619 DALYs for women and 19143 DALYs for men (10).

Currently, clinical trials are conducted on osteoporosis based on results measured by subjective tests. However, this indicator does not reflect the patient's normal daily activities and is not appropriate for assessing disability and symptoms. Additionally, recently some specific questionnaires on health-related quality of life, such as the Osteoporosis Assessment Questionnaire, have been aimed at determining the generic aspects of osteoporosis, i.e. these have been used as the main outcome in clinical studies on osteoporosis. However, they cannot explore in detail specific aspects of osteoporosis, for example, the fear of falling and suffering a bone fracture, the inability to adequately carry out domestic tasks, the ability to dress oneself adequately without help and despair about an uncertain future are all stressful for patients (11). These items are not included in the questionnaires and their omission could lead to an incomplete evaluation of the healthrelated quality of life of patients with osteoporosis.

While clinicians and researchers may apply a variety of questionnaires to assess health-related quality of life (12-15), the length of these instruments and the time they take to complete may limit their use. Consideration of greater efficiency, decreased burden on the respondent and clinical feasibility has led to the development of shorter questionnaires (16). Short questionnaires minimize a patient's time and effort and thus increase his or her willingness to complete it. For use in clinical practice, a valid, short, easy and understandable questionnaire is required and the ECOS-16 (Assessment of Health Related Quality of Life in Osteoporosis) questionnaire encompasses these characteristics (11). It is based on the combination of 2 disease-specific health-related quality of life questionnaires for women with osteoporosis: the Osteoporosis Quality of Life Questionnaire (OQLQ) and the Quality of Life Questionnaire of the European Foundation for Osteoporosis (QUALEFFO). The 16 items in the new questionnaire are divided qualitatively into 4 dimensions: pain, physical functioning, fear of illness and psychosocial functioning. Nevertheless, this is a unidimensional questionnaire according to the quantitative analysis. The score for each item ranges from 1 to 5 . ECOS-16 generates a single summary score obtained from the arithmetic mean of the items answered, consequently the total score ranges from 1 (best) to 5 (worst). It is a selfadministered questionnaire, apart from some special cases (vision difficulties or illiteracy) where it was acceptable for it to be administered by health care personnel or experienced interviewers.

There is no Farsi version of the ECOS-16 questionnaire; since quality of life depends on the cultural background of each country, the quality of life of Iranian women with osteoporosis should be evaluated using a questionnaire validated for Iranian society. Therefore, the aim of this study is to validate the ECOS-16 questionnaire for the evaluation of health-related quality of life in post-menopausal women with osteoporosis.

\section{Methods}

\section{Sample}

The minimum necessary sample size was based on Everitt's recommendations (17), thus, the ratio of sample size to number of questions (16 in this study) should be at least 10. A nonprobability sample (convenience sampling technique) of 220 patients with osteoporosis with low back pain (diagnosis validated by a physician) referred to a rheumatology clinic in Sanandaj was recruited into the study. Among patients routinely referred to the clinic, available patients were recruited. Overall, among the patients we approached, 10 people refused to participate, giving a response rate was $96 \%$ (220/230).

The inclusion criteria were determined according to the clinical and radiographic criteria: being female, aged 
$\geq 50$ years and diagnosed by $\mathrm{T}$-score $\leq-2.5$ measured at 2 points on the hip and spine. We excluded patients who had other rheumatic diseases, had participated in any physical therapy programme during the previous 6 months, had traumatic injuries (18) or had advanced cardiac or peripheral vascular disease.

The study was carried out from July to December 2013. The purpose of the study and the rights of human subjects for a research study were explained to the participants. All participants gave written informed consent and all information was strictly confidential and anonymous.

The literate patients completed the questionnaires independently and the patients who were illiterate or poorly educated were interviewed in a private room at the rheumatology clinic. The time needed to complete the questionnaires by literate patients was about $10-15$ min and each interview for the other participants lasted 15-20 min. Generally, most of the patients found the ECOS-16 easy to complete (for literate participants who completed the questionnaires themselves), easy to answer (for illiterate patients who were interviewed) and also relevant to their current osteoporosis-related problems. Most participants (>95\%) answered the questionnaires with no missing data.

\section{Developing the Farsi version}

A back-translation technique was used to develop the Farsi translation of ECOS-16. The questionnaire was translated into Farsi independently by 2 native translators of Farsi (1 rheumatologist with experience in osteoporosis and 1 professional translator). The translations obtained were discussed in a first consensus panel (a rheumatologist, 2 experts in health education and an epidemiologist with experience in osteoporosis) to realize the first preliminary version. This consensus version was translated back to English by a professional English translator who had not seen the original English version. The translations and back-translations were discussed in a second consensus panel to realize a second preliminary version. These consensus versions were completed by a group of 15 women aged 50-60 years who had osteoporosis recruited from the same clinic, but not participants in the study itself. This was to confirm that all items were understandable and included all the expected concepts and items without any redundancy. This was clear and well understood and therefore no cross-cultural modification was needed. Finally, a third consensus panel was formed to generate the final Farsi version of the ECOS-16 questionnaire (19).

\section{Statistical analysis}

Descriptive analysis was used to illustrate the basic features of the demographic data. Factor analysis embraces exploratory factor analysis and confirmatory factor analysis. Exploratory factor analysis is a statistical method used to discover the underlying structure of a relatively large set of variables (20). In this study, facture structure of the Farsi version of the ECOS-16 questionnaire was analysed using exploratory factor analysis. Exploratory factor analysis was used to achieve the study objectives.

In order to test the internal consistency of the ECOS-16 questionnaire, Cronbach's alpha coefficient was used. Statistical analysis was performed using SPSS, version 18.0 for Windows.

\section{Results}

The age range of the study participants was 50-75 (mean 59.9, standard deviation 7.0) years. A total of 200 (90.9\%) of the 220 participants were married and 190 (86.3\%) were housewives. More than half of the participants ( $n$ $=130,59.1 \%$ ) were illiterate. Family history of osteoporosis in participants' mothers was $13.6 \%(n=30)$. Most of the participants had no history of bone $(n=130,59.1 \%)$ or vertebral $(63.6 \%)$ fractures.

Internal consistency (Cronbach's alpha) estimation was 0.84. The KasierMeyer-Olkin measure of sampling statistic was 0.77 , so the data were suitable for factor analysis. Moreover, Barlett's test of sphericity was significant, i.e. the alternative hypothesis is confirmed, and there is a significant correlation between the variables.

In the evaluation of sharing value of variables or total variance with sharing value of factor of variables, the range was 53.1 to $92.7 \%$. Only 3 items (3 questions) were $<70 \%$, the greatest variances, 92.7 and $91.7 \%$, were shown for questions 12 and 14 respectively (Table1).

Most of the sharing values were $>50 \%$, which implies the ability of 5 factors in explaining the variance of each question (item). According to the results of a set of values derived from rotation, 5 factors can explain the variances. Using the Varimax rotation, these 5 factors can explain $80 \%$ of the variance (Table 2). We observed that from the 6th factor onwards changes in specific values were low, so it can be concluded that these 5 factors are the most important in explaining the variance.

The adoption of each item (or question) in the factor is based on the significant correlation between this item and other items in that factor. Therefore, it became clear that questions $3,4,6,8$, 9, 10 and 11 place in factor 1 , questions $1,2,5$ and 13 place in factor 2 , questions 12 and 14 place in factor 3 , questions 15 and 16 place in factor 4 and question 7 places in factor 5 .

\section{Discussion}

In the present study, the validity and reliability of the Farsi version of ECOS16 were evaluated on a sample of 220 patients with osteoporosis in Sanandaj. 


\begin{tabular}{lc}
\hline Table 1 Factor analysis: statistical analysis of ECOS-16 factors structure \\
\hline Question no. & Total variance $\%)$ \\
1 & 81.4 \\
2 & 71.6 \\
3 & 75.1 \\
4 & 87.6 \\
5 & 86.3 \\
6 & 86.9 \\
7 & 88.9 \\
8 & 64.5 \\
9 & 84.3 \\
10 & 82.9 \\
11 & 61.1 \\
12 & 92.7 \\
13 & 53.1 \\
14 & 91.7 \\
15 & 89.9 \\
16 & 90.7 \\
\hline
\end{tabular}

Our findings here suggest that the ECOS- 16 could be a valid, reliable and useful instrument wherever a brief, simple method of measuring the healthrelated quality of life, as in this type of patient population, is needed, and it has high internal consistency and a sound factorial structure. Regarding feasibility, the ECOS-16 was in general very good with no disturbing questions, few confusing questions, and a very low rate of missing data. The patients can complete the questionnaire in approximately 10 minutes. All fit indices were acceptable and the 4 factors were meaningful and interpretable.

Factor analysis showed that 2 factors of the ECOS-16 questionnaire accounted for 43.9 per cent of the explained variance. The first factor $(28.7 \%$ of the explained variance) represents the patient's perceived disability in major areas of daily life. The second factor ( $15.2 \%$ of the explained variance) reflects the patient's psychological troubles. Both dimension scales revealed satisfactory internal consistency.

The ECOS- 16 has been translated into many languages for non-Englishspeaking countries, e.g. Italy (16) and Turkey (21), which indicates the usefulness and reliability of this questionnaire of quality of life. In the Italian version, Salaffi et al. identified 4 factors (16), whereas in our study we identified 5 factors that can explain variance. In the Italian study, 2 components of the ECOS-16 questionnaire accounted for $88.4 \%$ of the explained variance. The first factor was $45.9 \%$ and the second

\begin{tabular}{lcc}
\hline \multicolumn{3}{l}{ Table 2 Variance of factors identified in Varimax rotation } \\
\hline Factor & Variance (\%) & Cumulative variance (\%) \\
\hline 1 & 28.7 & 28.7 \\
2 & 15.2 & 43.9 \\
3 & 14.1 & 58.0 \\
4 & 14.0 & 72.0 \\
5 & 7.9 & 80.0 \\
\hline
\end{tabular}

factor was $42.4 \%$ of the explained variance. So, the ECOS-16 questionnaire revealed satisfactory internal consistency (16). Cronbach's alpha values were $0.81-0.89$, similar to our result. Yilmaz et al., in a study on the Turkish version of the ECOS-16 questionnaire, indicated Cronbach's alpha was 0.90 (21), again similar to our result.

However, caution is needed before concluding that there is a causal relationship. Confounding factors may play a role in the observed association of reduced health-related quality of life in postmenopausal women with vertebral fractures, including sociodemographic conditions, education level, psychosocial status and other traditional risk factors. Self-reported chronic pain or reduced physical function, which are common complaints of elderly people, may be secondary symptoms of another condition, such as ischaemic heart disease, pain due to digestive diseases or chronic peripheral neuropathic pain (16).

In conclusion, our findings show that the Farsi version of the ECOS-16 questionnaire demonstrated acceptable validity and reliability. Thus, we expect that the Farsi version of this questionnaire will be useful for patients with osteoporosis in Iranian research and clinical settings. The Farsi version of the ECOS-16 questionnaire will increase the comparability of studies conducted in the Islamic Republic of Iran and in English speaking countries, and facilitate international collaboration in this field. It has potential applications in clinical practice and research. It is easy to administer, can be completed and scored quickly and is easily interpretable. It is suitable for assessing changes in treatment over time, for developing proper interventions or for determining the effect of interventions on various challenges. Responses to this questionnaire could also be used to develop an individualized approach in facilitating osteoporosis treatments and to improve quality of life. The items rated may 
warrant special consideration as these may become the basis for better quality of life.

It is suggested that further analysis may be used in considering potential biases, e.g. misclassification and selection bias (22). Also, consideration of other sources of bias is recommended in future studies; the results obtained may be regarded as closer to reality. It is possible that other factors (for example, confounding factors) affected our results, and in this research they have not been adjusted for.

Although our research was conducted at only one location, the study site was an Iranian city rheumatology clinic and our findings may be generalizable to many other areas in the country.
Acknowledgements

The study was approved by the Islamic Azad University, Sanandaj Branch. It was approved by the ethics committees of Arak University of Medical Sciences (IR.ARAKMU.REC.1394.385).

\section{Funding: None.}

Competing interests: None declared.

\section{References}

1. Hadi N, Shirali R. Knowledge and attitude of general practitioners to osteoporosis, Shiraz, 2004. J Hormozgan University of Medical Sciences. 2007;10(4):371-8.

2. Mahdavi Roshan M, Ebrahimi-Mameghani M, Ebrahimi AA, Ghaemmaghami J. Nutritional and biochemical factors of zinc and calcium in postmenopausal women with osteoporosis in Tabriz-2007. J Kermanshah University of Medical Sciences. 2008;12(3)

3. Gold D. The clinical impact of vertebral fractures: quality of life in women with osteoporosis. Bone. 1996;18(3):185-9. PMID:8777086

4. Bianchi ML, Orsini MR, Saraifoger S, Ortolani S, Radaelli G, Betti S. Quality of life in post-menopausal osteoporosis. Health Qual Life Outcomes. 2005;3:78. PMID:16321148

5. Kanis JA, World Health Organization Scientific Group. Assessment of osteoporosis at the primary health-care level. Technical Report. Sheffield, UK: World Health Organization Collaborating Centre for Metabolic Bone Diseases, University of Sheffield; 2007:64 (https://www.sheffield.ac.uk/FRAX/ pdfs/WHO_Technical_Report.pdf, accessed 21 July 2017).

6. Yazdani S, Iranpour A, Sohrabi M, Kolahi A, Sarbakhs P. The determination of clinical decision rule for estimation of mineral bone density in Iranian women. Iranian J Endocrinol Metab. 2009;10(5):511-8.

7. Keramat A, Larijani B, Adibi H, Hosseinnejad A, Chopra A, Patwardhan B. [Risk factors for osteoporosis in urban Iranian postmenopausal women (a center based study)]. Knowledge \& Health J. 2007;2(3):36-41 [in Farsi].

8. Rahnavard Z, Zolfaghari M, Kazemnejad A, Zarei L. [The relation between female teenagers' life style and osteoporosis prevention]. Hayat. 2006;12(2):53-61 [in Farsi].

9. Derakhshan S, Salehi R, Reshadmanesh N. Prevalence of osteoporosis, osteopenia and their related factors in post-menopausal women referring to Kurdistan densitometry center. Scientific J Kurdistan University Med Sci. 2006;11(2):59-67.

10. Soheili Azad AA, Yavari H, Azami M. Assessment of the costs of hip fractures in patients who referred to orthopedic clinic of Sina Hospital. Razi J Med Sci. 2005;12(47):83-92.

11. Badia X, Díez-Pérez A, Lahoz R, Lizán L, Nogués X, Iborra J. The ECOS-16 questionnaire for the evaluation of health related quality of life in post-menopausal women with osteoporosis. Health Qual Life Outcomes. 2004;2:41.

12. Hassanzadeh J, Nasimi B, Ranjbar Omrani G, Nazari M, Mohammadbeigi A. [Evaluating the quality of life of osteoporotic postmenopausal women]. Iranian J Endocrinol Metabol. 2012;14(3):234-40 [in Farsi].
13. Salaffi F, Cimmino MA, Malavolta N, Carotti M, Di Matteo L, Scendoni $\mathrm{P}$, et al. The burden of prevalent fractures on healthrelated quality of life in postmenopausal women with osteoporosis: the IMOF study. J Rheumatol. 2007;34(7):1551-60. PMID:17516618

14. Cook DJ, Guyatt GH, Adachi JD, Epstein RS, Juniper EF, Austin $\mathrm{PA}$, et al. Development and validation of the mini-osteoporosis quality of life questionnaire (OQLQ) in osteoporotic women with back pain due to vertebral fractures. Osteoporosis Quality of Life Study Group. Osteoporos Int. 1999;10:207-13. PMID:10525712

15. Badia X, Diez-Pérez A, Alvarez-Sanz C, Diaz-López B, DiazCuriel M, Guillén F, et al. Measuring quality of life in women with vertebral fractures due to osteoporosis: a comparison of the OQLQ and QUALEFFO. Qual Life Res. 2001;10(4):307-17. PMID:11763244

16. Salaffi F, Malavolta N, Cimmino M, Di Matteo L, Scendoni P, Carotti $M$, et al. Validity and reliability of the Italian version of the ECOS-16 questionnaire in postmenopausal women with prevalent vertebral fractures due to osteoporosis. Clin Exp Rheumatol. 2007;25(3):390-403. PMID:17631735

17. MacCallum RC, Widaman KF, Zhang S, Hong S. Sample size in factor analysis. Psychol Methods. 1999; 4(1):84-99.

18. Ulivieri F. Back pain treatment in post-menopausal osteoporosis with vertebral fractures. Aging Clin Exp Res. 2007 19(3):21-3. PMID:18180603

19. Nadrian H, Moghimi N, Nadrian E, Moradzadeh R, Bahmanpour K, Iranpour A, et al. Validity and reliability of the Persian versions of WOMAC Osteoarthritis Index and Lequesne Algofunctional Index. Clin Rheumatol. 2012;31(7):1097-102. PMID:22526476

20. Soleimani H, Bashash L. Factor structure, validity and reliability of the Maternal Emotional Styles Questionnaire (MESQ). Knowledge \& Research in Applied Psychology. 2012;13(47):3948.

21. Yilmaz F, Dogu B, Sahin F, Sahin T, Kuran B. Reliability and validity of the Turkish version of the ECOS 16 questionnaire in postmenopausal osteoporosis. Eur J Phys and Rehabil Med. 2009;45(4):521-6. PMID:20032911

22. Moradzadeh R, Mansournia MA, Baghfalaki T, Ghiasvand R, Noori-Daloii MR, Holakouie-Naieni K. Misclassification adjustment of family history of breast cancer in a case-control study: a Bayesian approach. Asian Pac J Cancer Prev. 2015;16(18):82216. PMID:26745064 